\title{
Anhydrous Aluminum Chloride Catalyzed Methylene Group Inclusion: Mechanistic, Spectral and Single Crystal X-Ray Structural Study on Methanediyl Bis(Cyclohexylmethylcarbamodithioate)
}

\author{
K. Ramalingam ${ }^{1, a^{*}}$, C. Rizzoli ${ }^{2, b}$, G.S. Sivagurunathan ${ }^{3, c}$, S. Sivasekar ${ }^{1}$, \\ T. Rajaraman ${ }^{1}$ and M. Prabu ${ }^{1}$ \\ ${ }^{1}$ Department of Chemistry, Annamalai University, Annamalainagar 608 002, Tamil Nadu, India. \\ ${ }^{2}$ Department of General and Inorganic Chemistry, University of Parma, Parma-43100, Italy \\ ${ }^{3}$ Department of Chemistry, Knowledge Institute of Technology, Salem 637 504, Tamil Nadu, India \\ akrauchem@yahoo.coml, ${ }^{\mathrm{b}}$ corrado.rizzoli@unipr.it, ${ }^{\mathrm{c}} \mathrm{gssivapalam@gmail.com}$
}

Keywords: Methylene; anhydrous $\mathrm{AlCl}_{3}$; NMR; Mass spectrum; single crystal X-ray.

\begin{abstract}
In this study anhydrous $\mathrm{AlCl}_{3}$ is used as a catalyst for the inclusion of a methylene group in to cyclohexylmethyldithiocarbamic acid to form methanediyl bis(cyclohexylmethylcarbamodithioate). Dichloromethane is used as a methylene group bearer in the reaction. A suitable mechanistic pathway involving ${ }^{+} \mathrm{CH}_{2} \mathrm{Cl}$ is discussed. FTIR, NMR and Mass spectral techniques have been used in the analysis. Single crystal X-ray structure of the compound was determined. FTIR spectrum of the compound showed $v_{\mathrm{c}-\mathrm{s}}$ band at $1073 \mathrm{~cm}^{-1}$ and $v_{\mathrm{C}-\mathrm{H}}$ vibrations appeared at 2853 and $2928 \mathrm{~cm}^{-1}$. Thioureide stretching band was observed at $1473 \mathrm{~cm}^{-1}$. The molecular ion peak in the Mass spectroscopy confirmed the proposed formula. $\mathrm{H}^{1} \mathrm{NMR}$ spectrum of the compound showed a signal at 4.33(s) ppm for $\alpha-\mathrm{CH}$ of the cyclohexyl ring and $\mathrm{CH}_{3}$ protons attached to nitrogen appeared at $3.40 \mathrm{ppm}$. Methylene proton $\left(\mathrm{S}-\mathrm{CH}_{2}-\mathrm{S}\right)$ signal appeared at $3.16 \mathrm{ppm}$ which is largely deshielded by the presence of two electronegative sulphur atoms on either side. The characteristic methylene carbon $\left(\mathrm{S}-\mathrm{CH}_{2}-\mathrm{S}\right)$ signal appeared at $45.46 \mathrm{ppm}$ in the ${ }^{13} \mathrm{C}$ NMR spectrum. Single crystal X-ray structural analysis of the compound showed it to be monomeric. Methylene carbon in $\mathrm{S}-\mathrm{CH}_{2}-\mathrm{S}, \mathrm{C}(9)$ is tetrahedrally bonded to two hydrogen atoms and two sulphur atoms $\mathrm{S}(2), \mathrm{S}(3)$. The molecule stacks its cyclohexyl rings along 'c' axis of the unit cell. Short contacts in the form of supramolecular interactions such as C---S and S---S exist in the solid state at 3.49 and 3.50 Å respectively.
\end{abstract}

\section{Introduction}

Organosulphur compounds are important intermediates in organic synthesis. Recently, a new reaction protocol was developed that consists of a reductive lithiation of alkyl or arylthioesters [1-5]. Lewis acids serve as a catalyst for the methylene group inclusion reaction of thiols. Reactions of thiols with dimethoxymethane in the presence of four equivalents of Lewis acids, such as $\mathrm{AlCl}_{3}$, $\mathrm{TiCl}_{4}$ and $\mathrm{SnCl}_{4}$ were investigated [6-12]. Aluminum hydrogen sulfate acts as a catalyst for the efficient synthesis of 3,4-dihydropyrimidin-2(1H)-ones via the condensation of aromatic aldehydes, $\beta$-keto esters and urea (or thiourea) in methanol under solvent-free conditions [13]. Though there is a growing importance of dithioacetals or sulfur-stabilized carbanions in organic synthetic chemistry. Generally bis(alkyl or arylthio)methanes are prepared by the reaction of diiodomethane with sodium thioalkoxide or thiophenoxide $[14,15]$ and in this case diiodomethane is used as a methyl inclusion agent as it can easily give the methylene group by the abstraction of iodine atoms by Lewis acid. The rate order to synthesize dithioacetals in the presence of Lewis acids was decreasing in the order: $\mathrm{TiCl}_{4} / \mathrm{Zn}$ [Ti] $>\mathrm{AlCl}_{3}>\mathrm{TiCl}_{4}>\mathrm{SnCl}_{4}$ [16]. The formation of $\mathrm{S}-\mathrm{CH}_{2}-\mathrm{S}$ bond between two $\mathrm{N}-\mathrm{CBZ}$-protected cysteins, is having great significance as there is an immense interest due to their biological activity [17]. In the present investigation, methanediyl bis(cyclohexylmethylcarbamodithioate) was prepared by using anhydrous $\mathrm{AlCl}_{3}$ as a catalyst and dichloromethane as methylene bearing source for inserting methylene group in cyclohexylmethyldithiocarbamic acid and the product is characterized by IR, mass, $\mathrm{nmr}$ and single crystal XRD techniques. 


\section{Experimental}

Cyclohexylmethyl amine (Sigma-Aldrich, 99.7\%), carbon disulfide and dichloromethane (Sd fine Chemicals, India) were used in the preparation. All the reagents and solvents employed were commercially available analytical grade materials and were used as supplied without further purification. IR spectra were recorded as $\mathrm{KBr}$ pellets on $\mathrm{ABB}$ Bomen MB 104 spectrometer (range: 4000-400 $\mathrm{cm}^{-1}$ ). NMR spectra were recorded on a Bruker $400 \mathrm{MHz}$ spectrometer at room temperature using $\mathrm{CDCl}_{3}$ as solvent. Mass spectra were recorded on a VG Autospec GEIFAB and a Hewlett Packard MS-Engine thermospray and ionization by electron impact at $70 \mathrm{eV}$.

Single crystal X-ray crystallography

Intensity data were collected at ambient temperature $(295 \mathrm{~K})$ on Bruker SMART $1000 \mathrm{CCD}$ diffractometer using graphite monochromated MoK $\alpha$ radiation $(\lambda=0.71073 \AA)$. Data were corrected for absorption using the SADABS program and $\omega$-scan technique was used for data collection [8, 9]. The structures were solved by SIR97 [10] and were refined by full matrix least squares with SHELXL-97 [11]. All the non-hydrogen atoms were refined anisotropically and the hydrogen atoms were fixed geometrically. ORTEP-3 program was used for drawing the molecular plots [12].

\section{Results and discussion}

Synthesis of methanediyl bis(cyclohexylmethylcarbamodithioate)

Cyclohexylmethyl amine $(0.27 \mathrm{~mL}, 2 \mathrm{~m} \mathrm{~mol})$ in dichloromethane $(25 \mathrm{~mL})$ and carbon disulfide $(0.16 \mathrm{~mL}, 2 \mathrm{~m} \mathrm{~mol})$ in dichloromethane were mixed under ice cold condition $\left(0-5^{\circ} \mathrm{C}\right)$ to obtain yellow cyclohexylmethyldithiocarbamic acid solution. To this solution, anhydrous aluminum chloride $(0.2 \mathrm{~g}, 2 \mathrm{~m} \mathrm{~mol})$ was added slowly with vigorous stirring using magnetic stirrer, for about one and half an hour. Colourless solid formed was removed by filtration and the filtrate was kept for slow evaporation. On evaporation of the solvent a pale yellow solid appeared (Scheme 1) which was than recrystallized for three times with acetonitrile. Yield: $56 \%$, m. p.: $81{ }^{\circ} \mathrm{C}$. Elemental analysis: \% Anal. Calcd., for $\mathrm{C}_{17} \mathrm{H}_{30} \mathrm{~N}_{2} \mathrm{~S}_{4}$ (390.7): C, 52.26; H, 7.74; N, 7.17. Found (\%): C, 52.22; $\mathrm{H}, 7.71 ; \mathrm{N}, 7.14$.
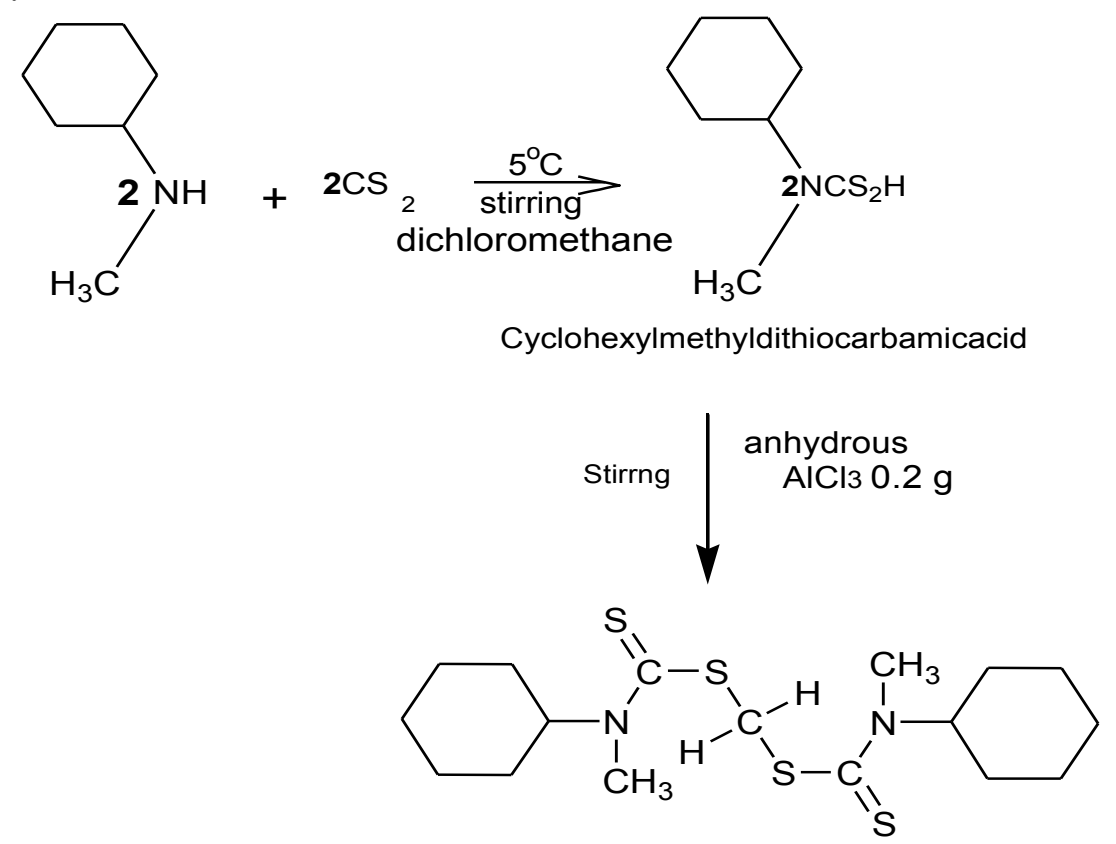

methanediyl bis(cyclohexylmethylcarbamodithioate)

Scheme 1. Formation of methanediyl bis(cyclohexylmethylcarbamodithioate)

Mechanism of the reaction is shown in Scheme 2. In this reaction aluminum chloride is used as a methylene inclusion catalyst and it is able to abstract the chlorine atom in step (1) from 
dichloromethane and forms carbocation (electrophile) due to its Lewis acidity. $\mathrm{AlCl}_{4}{ }^{-}$has the tendency to produce dithiocarbamate anion from corresponding dithiocarbamic acid as in step (2). In step (3), chloromethylcyclohexylmethylcarbamodithioate is formed. In step (4), $\mathrm{AlCl}_{3}$ abstracts a hydrogen from chloromethylcyclohexylmethylcarbamodithioate and the corresponding carbocation is formed. The carbocation interacts with another dithiocarbamate anion (step (5)) to form methanediyl bis(cyclohexyl methylcarbamodithioate). The present method is a relatively simple process in which a methylene group is inserted to form an $-\mathrm{S}-\mathrm{CH}_{2}-\mathrm{S}-$ moiety.

Spectral studies

FTIR and Mass spectrum

In the IR spectrum, characteristic thioureide stretching bands are observed at $1473 \mathrm{~cm}^{-1}$ for the alkylated compound, which is a clear evidence for the partial double bonded nature of C-N bond. The $v_{\mathrm{c}-\mathrm{s}}$ band appears at $1073 \mathrm{~cm}^{-1}$ and $v_{\mathrm{C}-\mathrm{H}}$ vibrations appear at 2853 and $2928 \mathrm{~cm}^{-1}$ respectively (Figure 1). In the mass spectrum (Figure 2), the molecular ion peak is observed at $\left(\mathrm{M}^{+}=391.83\right.$ ) which clearly confirmed the formation of the methylene inserted compound.

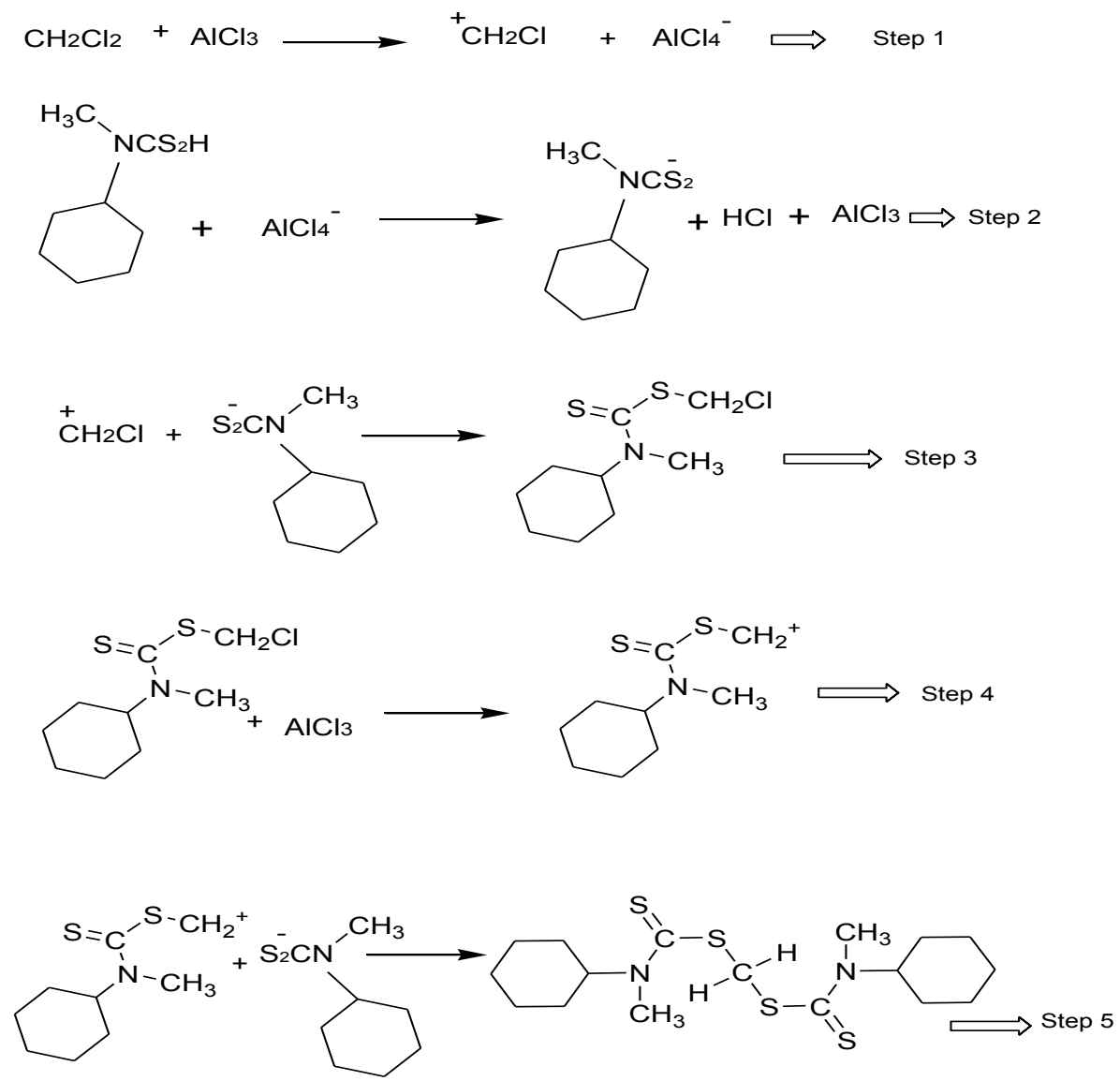

Scheme 2. Mechanism of formation of methanediyl bis(cyclohexylmethylcarbamodithioate) 


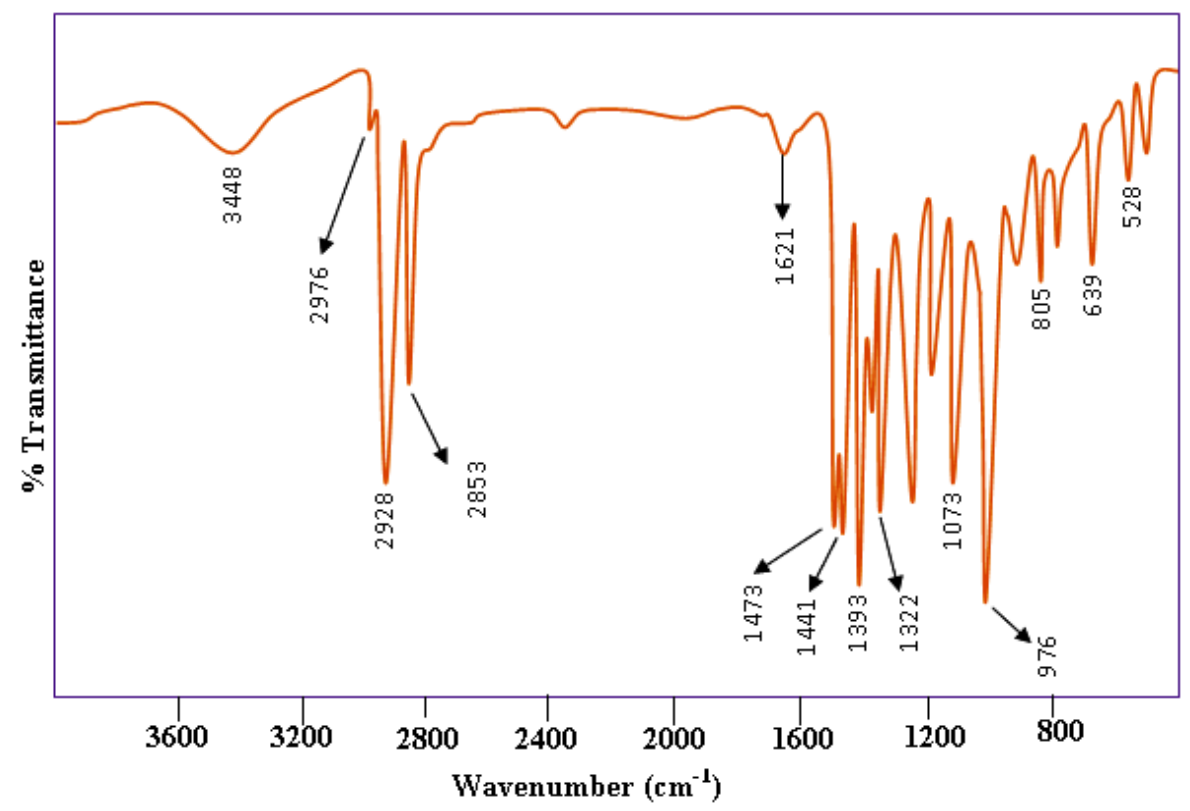

Figure 1. FTIR spectrum of methanediyl bis(cyclohexylmethylcarbamodithioate)

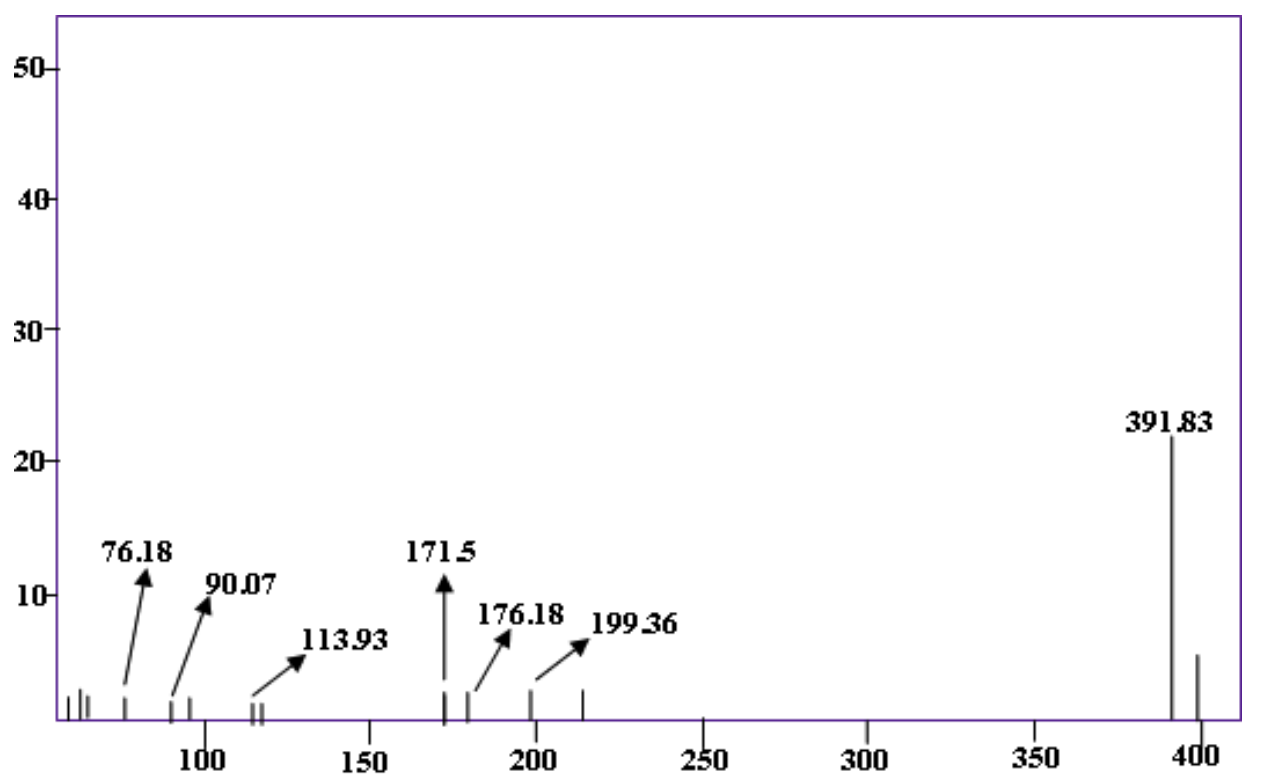

Figure 2. Mass spectrum of methanediyl bis(cyclohexylmethylcarbamodithioate)

NMR spectral analysis

$\mathrm{H}^{1} \mathrm{nmr}$ spectrum of the compound (Figure 3) showed a signal at 4.33(s) ppm for $\alpha-\mathrm{CH}$ of the cyclohexyl ring and $-\mathrm{CH}_{3}$ protons attached to nitrogen appeared at $3.40 \mathrm{ppm}$ with a proton integration value of three. A characteristic methylene proton $\left(\mathrm{S}-\mathrm{CH}_{2}-\mathrm{S}\right)$ signal appeared at $3.16 \mathrm{ppm}$ which is largely deshielded by the presence of two electronegative sulphur atoms on either side. The cyclohexyl ring protons appeared in the range of 1.10-1.84 ppm. All the equatorial protons are deshielded to a large extent compared to the axial protons. The ${ }^{13} \mathrm{C} \mathrm{nmr}$ spectrum of the compound (Figure 4) showed the characteristic thioureide signal at $195.5 \mathrm{ppm}$ [26]. The $\alpha$ - carbon (cyclohexyl ring) appeared at $62.53 \mathrm{ppm}$ and $\mathrm{N}-\mathrm{C}\left(\mathrm{H}_{3}\right)$ carbon appeared at $37.74 \mathrm{ppm}$. The characteristic methylene carbon $\left(\mathrm{S}_{-} \mathrm{CH}_{2}-\mathrm{S}\right)$ signal appeared at $45.46 \mathrm{ppm}$. Cyclohexyl carbons appeared in the range: $25.20-30.21 \mathrm{ppm}$. In the DEPT spectrum (Figure 5) of the compound, the characteristic methylene carbon $\left(\mathrm{S}-\mathrm{CH}_{2}-\mathrm{S}\right)$ appeared at $45.46 \mathrm{ppm}$. 
Single crystal X-ray structural analysis

Details of data collection and refinement parameters of the compound are given in Table 1. Selected bond distances and angles are given in Table 2. ORTEP diagram of the compound is given in Figure 6. Packing diagram of the compound is shown in Figure 7.

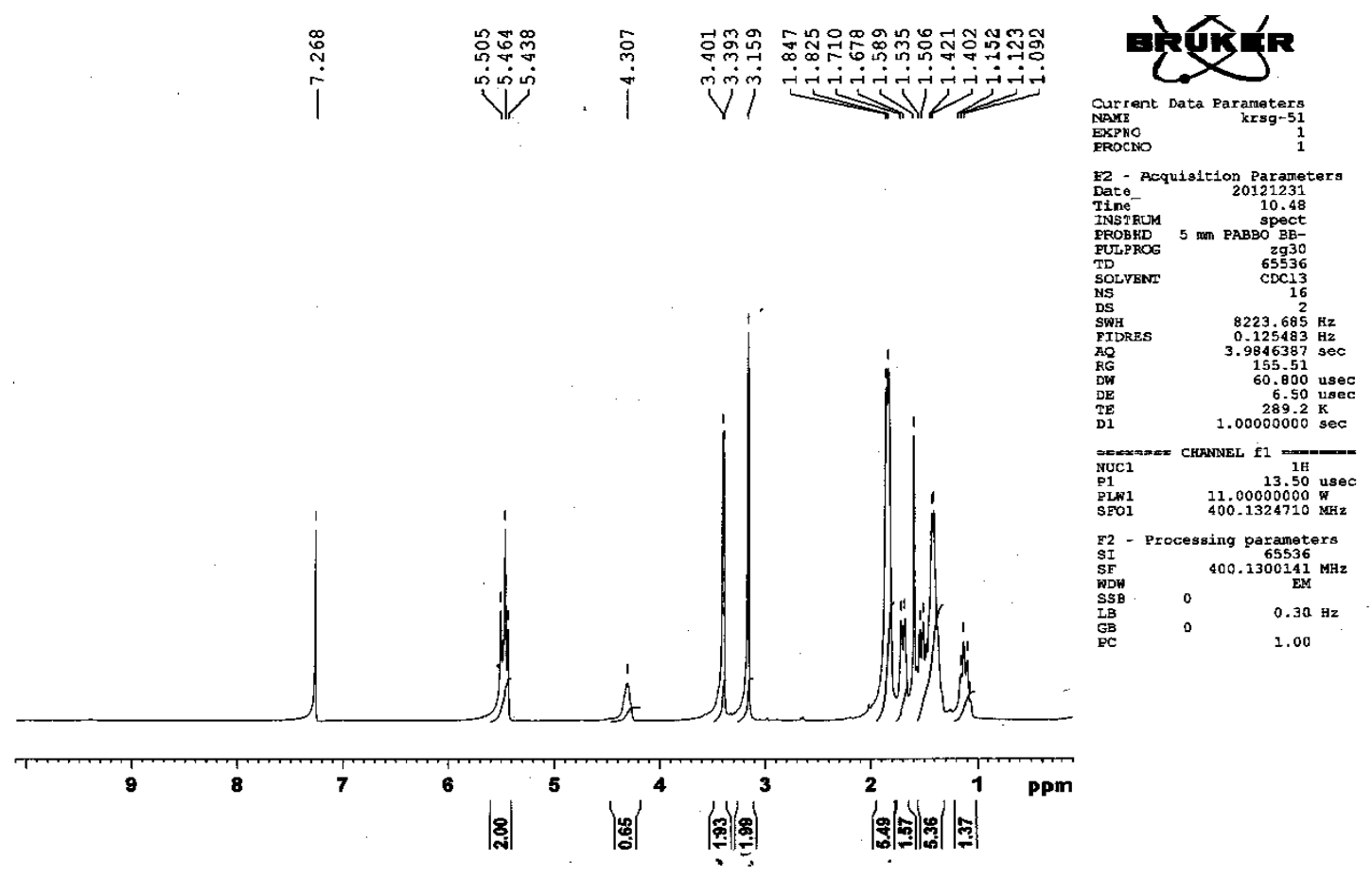

Figure 3. $\mathrm{H}^{1} \mathrm{NMR}$ spectrum of methanediyl bis(cyclohexylmethylcarbamodithioate)

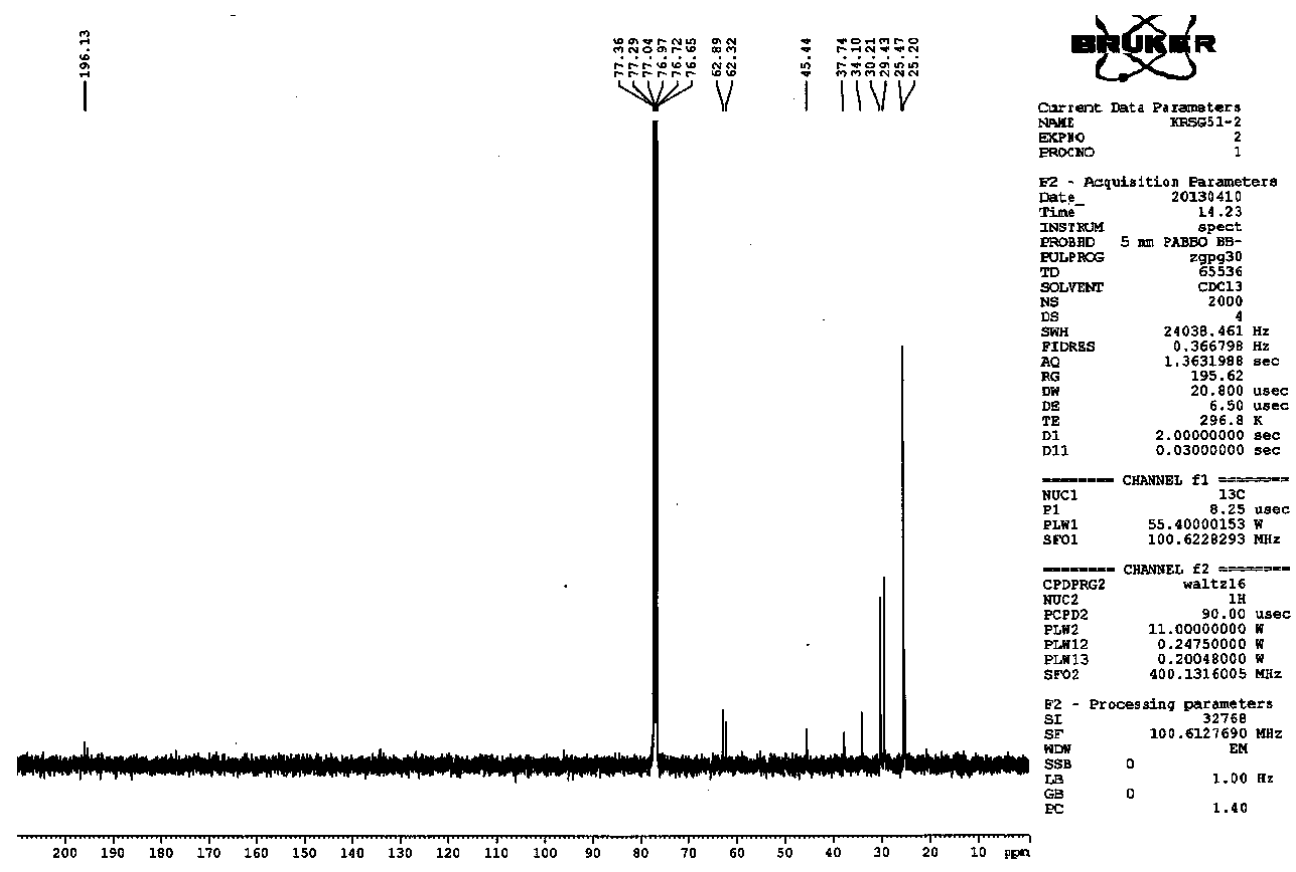

Figure $4 .{ }^{13} \mathrm{C}$ NMR spectra of methanediyl bis(cyclohexylmethylcarbamodithioate) 


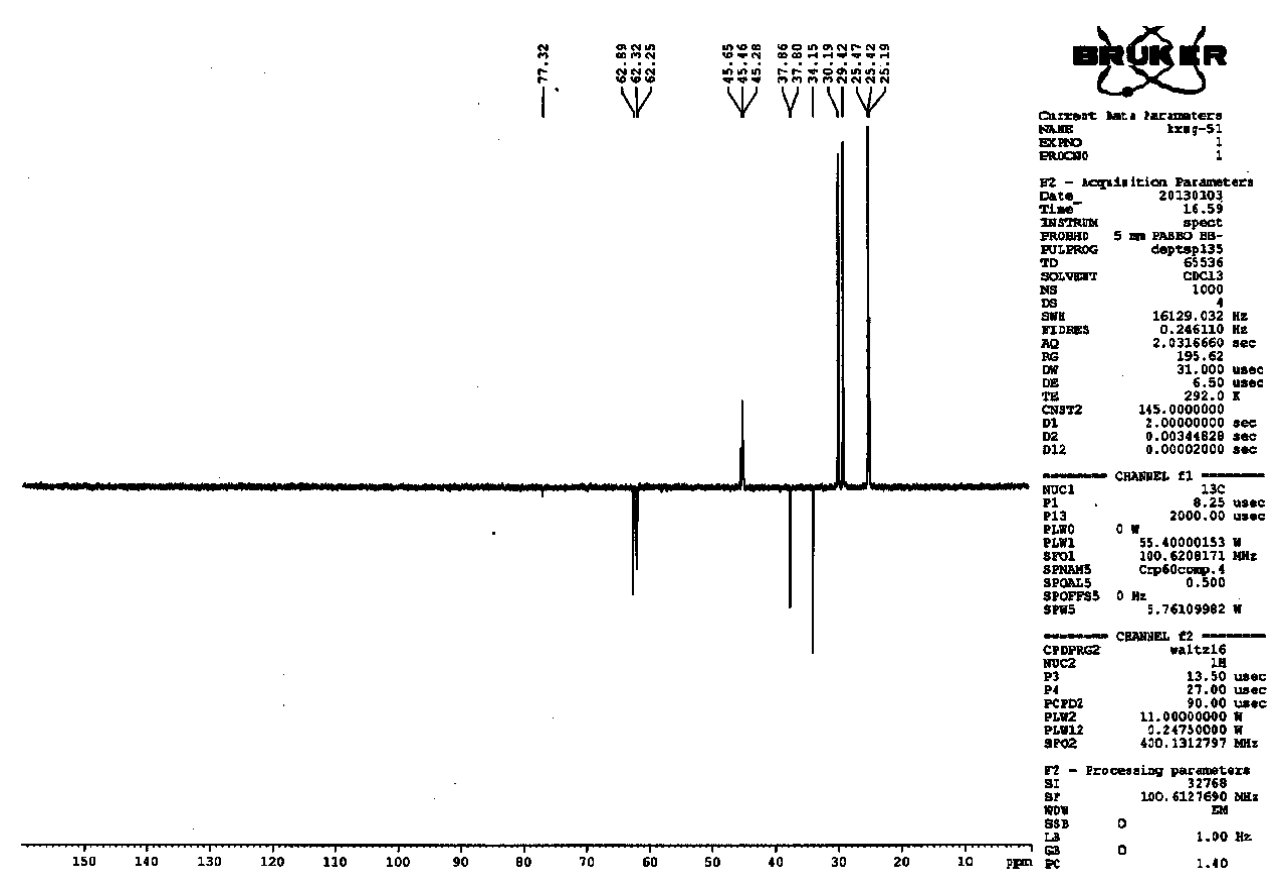

Figure 5. DEPT spectrum of methanediyl bis(cyclohexylmethylcarbamodithioate)

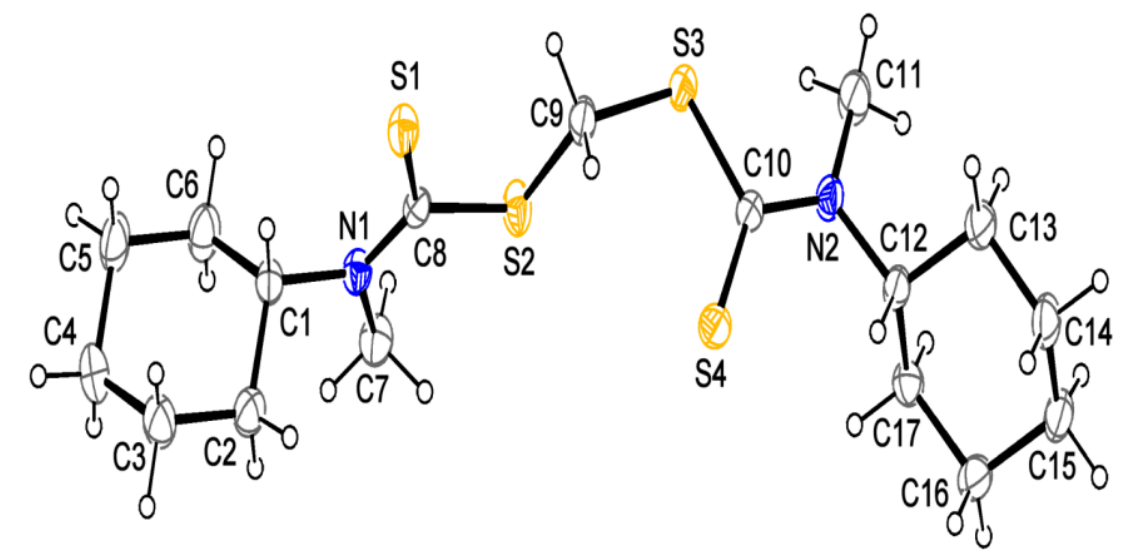

Figure 6. ORTEP of methanediyl bis(cyclohexylmethylcarbamodithioate) (50\% probability ellipsoids)

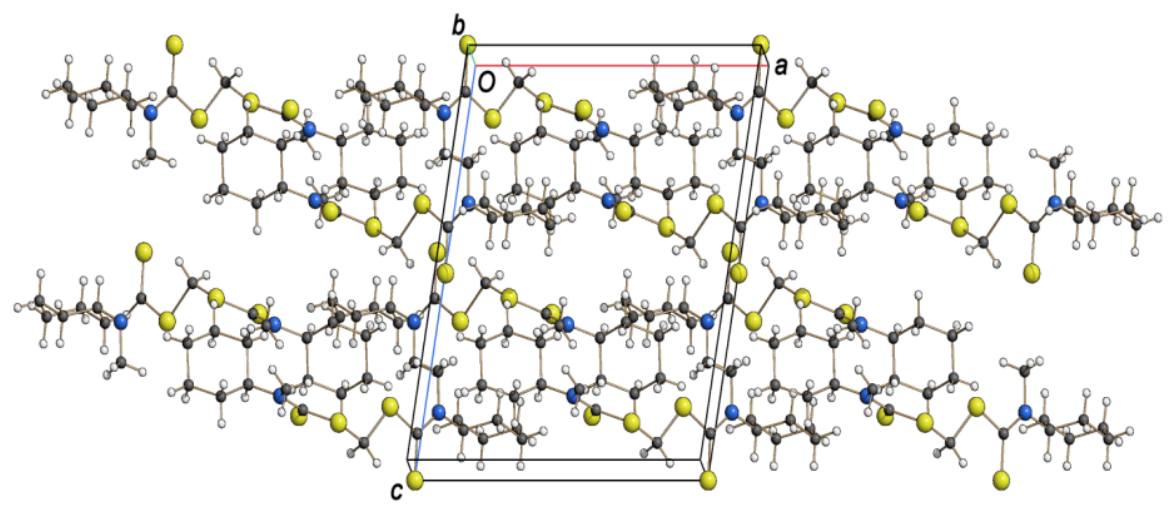

Figure 7. Packing diagram of methanediyl bis(cyclohexylmethylcarbamodithioate) 
The compound is monomeric in nature. Four formula units are present in one unit cell. Methylene carbon in $\mathrm{S}-\mathrm{CH}_{2}-\mathrm{S}, \mathrm{C}(9)$ is tetrahedrally bonded to two hydrogen atoms, $\mathrm{H}(9 \mathrm{~A}), \mathrm{H}(9 \mathrm{~B})$ and two sulphur atoms, $\mathrm{S}(2), \mathrm{S}(3)$. The $\mathrm{C}(9)-\mathrm{S}(2)$ and $\mathrm{C}(9)-\mathrm{S}(3)$ bond distances around the methylene carbon are 1.8072(16) and 1.7934(16) $\AA$ respectively. The two hydrogen atoms subtend $108.19(1)^{\circ}$ at $\mathrm{C}(9)$. However, $\mathrm{S}(2)-\mathrm{C}(9)-\mathrm{S}(3)$ angle is $109.53(1)^{\circ}$. The partial double bonded distances do not show large changes compared to the previous reports. [27-30]. The molecule stacks its cyclohexyl rings along 'c' axis of the unit cell as shown in Figure 8. Short contacts in the form of supramolecular interactions such as C---S and S---S exist in solid state at 3.49 and $3.50 \AA$ respectively, which are marginally less than the sum of their van der Waals radii.

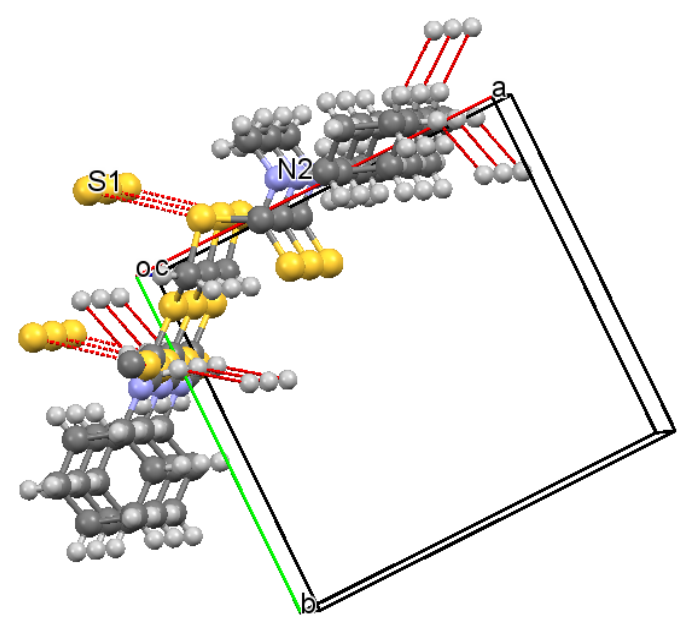

Figure 8. Stacking of cyclohexyl rings and the short contacts in methanediyl bis(cyclohexylmethylcarbamodithioate)

\section{Conclusions}

In this report anhydrous $\mathrm{AlCl}_{3}$ is used as a catalyst for the inclusion of a methylene group in to cyclohexylmethyldithiocarbamic acid to form methanediyl bis (cyclohexylmethylcarbamodithioate). Dichloromethane is used as a methylene group bearer in the reaction. In the FTIR spectrum of the compound, the $v_{\mathrm{c}-\mathrm{s}}$ band appears at $1073 \mathrm{~cm}^{-1}$ and $v_{\mathrm{C}-\mathrm{H}}$ vibrations appear at 2853 and $2928 \mathrm{~cm}^{-1}$. Thioureide stretching band is observed at $1473 \mathrm{~cm}^{-1}$. The molecular ion peak in Mass spectroscopy confirmed the proposed formula. $\mathrm{H}^{1} \mathrm{nmr}$ spectrum of the compound showed a signal at 4.33(s) ppm for $\alpha-\mathrm{CH}$ of the cyclohexyl ring and $-\mathrm{CH}_{3}$ protons attached to nitrogen appeared at $3.40 \mathrm{ppm}$. Methylene proton $\left(\mathrm{S}_{-} \mathrm{CH}_{2}-\mathrm{S}\right)$ signal appeared at 3.16 $\mathrm{ppm}$ which is largely deshielded by the presence of two electronegative sulphur atoms on either side. The characteristic methylene carbon $\left(\mathrm{S}-\mathrm{CH}_{2}-\mathrm{S}\right)$ signal appeared at $45.46 \mathrm{ppm}$ in the ${ }^{13} \mathrm{C} \mathrm{NMR}$ spectrum. Single crystal X-ray structural analysis of the compound showed it to be monomeric. Methylene carbon in $\mathrm{S}-\mathrm{CH}_{2}-\mathrm{S}, \mathrm{C}(9)$ is tetrahedrally bonded to two hydrogen atoms and two sulphur atoms $\mathrm{S}(2), \mathrm{S}(3)$. The molecule stacks its cyclohexyl rings along 'c' axis of the unit cell. Short contacts in the form of supramolecular interactions such as C---S and S---S exist in solid state at 3.49 and $3.50 \AA$ respectively. 


\section{Additional information}

Table 1. Crystal data, data collection and refinement parameters of methanediyl bis(cyclohexylmethylcarbamodithioate)

\begin{tabular}{ll}
\hline Empirical formula & $\mathrm{C}_{17} \mathrm{H}_{30} \mathrm{~N}_{2} \mathrm{~S}_{4}$ \\
\hline Formula weight & 390.67 \\
Crystal dimensions $(\mathrm{mm})$ & $0.44 \times 0.34 \times 0.27$ \\
Crystal system & Monoclinic \\
Colour & Colourless \\
Space group & $\mathrm{P} 21 / \mathrm{c}$ \\
$\mathrm{a} / \AA$ & $12.1995(7)$ \\
$\mathrm{b} / \AA$ & $11.1215(6)$ \\
$\mathrm{c} / \AA$ & $14.9494(8)$ \\
$\alpha /{ }^{\circ}$ & 90 \\
$\beta /{ }^{\circ}$ & 99.6578 \\
$\gamma /{ }^{\circ}$ & 90 \\
$\mathrm{U} / \AA^{3}$ & $1999.54(19)$ \\
$\mathrm{Z}$ & 4 \\
$\mathrm{D}_{\mathrm{c}} / \mathrm{g}$ cm & \\
$\mu / \mathrm{cm}^{-1}$ & 1.298 \\
$\mathrm{~F}(000)$ & 0.476 \\
$\theta /{ }^{\circ}$ & 840 \\
Diffractometer & $4.24-26.30$ \\
Scan type & $\mathrm{Bruker} \mathrm{APEX-II} \mathrm{CCD}$ \\
Index ranges & $\omega \mathrm{scans}$ \\
Reflections collected & $-14 \leq \mathrm{h} \leq 14 ;-13 \leq \mathrm{k} \leq 13 ;-18 \leq 1 \leq 18$ \\
Unique reflections & 20869 \\
Observed reflections $\mathrm{F}_{\mathrm{o}}>4 \sigma\left(\mathrm{F}_{\mathrm{o}}\right)$ & 3407 \\
Weighting scheme & 3727 \\
Number of parameters refined & $\mathrm{w}=1 /\left[\sigma^{2}\left(\mathrm{~F}_{\mathrm{o}}{ }^{2}\right)+(0.0224 \mathrm{P})^{2}+46.1051 \mathrm{P}\right]$, where $\mathrm{P}=\left(\mathrm{F}_{\mathrm{o}}{ }^{2}+2 \mathrm{~F}_{\mathrm{c}}{ }^{2}\right) / 3$ \\
Final R, $\mathrm{R}_{\mathrm{w}}$ (observed data) & $0.0296,0.0768$ \\
Goodness-of-fit & 1.043 \\
\hline
\end{tabular}

Table 2. Selected bond distances and bond angles

\begin{tabular}{cccc}
\hline \multicolumn{2}{c}{ Selected bond distances $(\AA \mathbf{\AA})$} & \multicolumn{2}{c}{ Selected bond angles $\mathbf{(}^{\circ}$ ) } \\
\hline $\mathrm{C}(8)-\mathrm{S}(1)$ & $1.6651(14)$ & $\mathrm{C}(8)-\mathrm{S}(2)-\mathrm{C}(9)$ & $102.15(7)$ \\
$\mathrm{C}(8)-\mathrm{S}(2)$ & $1.7782(14)$ & $\mathrm{C}(10)-\mathrm{S}(3)-\mathrm{C}(9)$ & $103.93(7)$ \\
$\mathrm{C}(9)-\mathrm{S}(2)$ & $1.8072(16)$ & $\mathrm{S}(3)-\mathrm{C}(9)-\mathrm{S}(2)$ & $109.53(9)$ \\
$\mathrm{C}(10)-\mathrm{S}(3)$ & $1.7897(15)$ & $\mathrm{S}(2)-\mathrm{C}(9)-\mathrm{H}(9 \mathrm{~A})$ & $109.8(1)$ \\
$\mathrm{C}(9)-\mathrm{S}(3)$ & $1.7934(16)$ & $\mathrm{S}(3)-\mathrm{C}(9)-\mathrm{H}(9 \mathrm{~B})$ & $109.8(1)$ \\
$\mathrm{C}(10)-\mathrm{S}(4)$ & $1.6613(15)$ & $\mathrm{C}(8)-\mathrm{N}(1)-\mathrm{C}(7)$ & $121.42(13)$ \\
$\mathrm{N}(1)-\mathrm{C}(8)$ & $1.3363(19)$ & $\mathrm{C}(8)-\mathrm{N}(1)-\mathrm{C}(1)$ & $121.37(12)$ \\
$\mathrm{N}(1)-\mathrm{C}(7)$ & $1.4671(18)$ & $\mathrm{C}(7)-\mathrm{N}(1)-\mathrm{C}(1)$ & $117.16(12)$ \\
$\mathrm{N}(1)-\mathrm{C}(1)$ & $1.4822(19)$ & $\mathrm{C}(10)-\mathrm{N}(2)-\mathrm{C}(11)$ & $122.10(13)$ \\
$\mathrm{N}(2)-\mathrm{C}(10)$ & $1.3351(19)$ & $\mathrm{C}(10)-\mathrm{N}(2)-\mathrm{C}(12)$ & $121.20(12)$ \\
$\mathrm{N}(2)-\mathrm{C}(11)$ & $1.466(2)$ & $\mathrm{C}(11)-\mathrm{N}(2)-\mathrm{C}(12)$ & $116.65(12)$ \\
$\mathrm{N}(2)-\mathrm{C}(12)$ & $1.4842(18)$ & $\mathrm{N}(1)-\mathrm{C}(8)-\mathrm{S}(1)$ & $125.50(11)$ \\
& & $\mathrm{N}(1)-\mathrm{C}(8)-\mathrm{S}(2)$ & $113.64(10)$ \\
& & $\mathrm{S}(1)-\mathrm{C}(8)-\mathrm{S}(2)$ & $120.85(9)$ \\
& & $\mathrm{N}(2)-\mathrm{C}(10)-\mathrm{S}(4)$ & $125.53(11)$ \\
& & $\mathrm{N}(2)-\mathrm{C}(10)-\mathrm{S}(3)$ & $111.93(11)$ \\
& & $\mathrm{S}(4)-\mathrm{C}(10)-\mathrm{S}(3)$ & $122.53(9)$ \\
\hline
\end{tabular}




\section{References}

[1] T. Cohen, M. Bhupathy, Organoalkali compounds by radical anion induced reductive metalation of phenyl thioethers, Acc. Chem. Res. 22 (1989) 152-161.

[2] C.G. Screttas, Stoichiometry and Synthetic Utility of the Reaction of Alkyl Halides with Lithium Dihydronaphthylides, J. Chem. Soc., Chem. Commun. (1972) 752-753.

[3] T. Cohen, J.R. Matz, Reductive Lithiation of Some Thioketals Using Lithium 1(Dimethylamino)naphthalenide, Synth. Commun. 10 (1980) 311-317..

[4] N. Kennedy, P. Liu, T. Cohen, Fundamental Difference in Reductive Lithiations with Preformed Radical Anions versus Catalytic Aromatic Electron-Transfer Agents: N,NDimethylaniline as an Advantageous Catalyst, Angew. Chem. Int. Ed. Engl. 4(55) (2016) 383-386.

[5] M.A. Perry, S.D. Rychnovsky, Generation, structure and reactivity of tertiaryorganolithium reagents, Natural Product Reports. 32 (2015) 517-533.

[6] J.H. Lee, H.J. Jeong, C.K. Jin, S.H. Jang, M.K. Kim, Y.J. Yoon and S.G. Lee. Development of a Novel Method for the Preparation of Dithioacetal in the Presence of Titanium(IV) Chloride/Zinc in Dimethoxymethane, Bull. Korean Chem. Soc. 26 (2005) 811-814.

[7] E.J. Corey, D. Seebach, Angew. Chem., Int. Ed. Engl. 4 (1965) Proceedings of 'The Chemistry of Natural Products: Main Lectures Presented at the Fourth International Symposium on the Chemistry of Natural Products Held in Stockholm, Sweden, 26 June-2 July, 1966.

[8] C. G. Screttas, M. Micha-Screttas, Hydrolithiation of .alpha.-olefins by a regiospecific twostep process. Transformation of alkyl phenyl sulfides to alkyllithium reagents, J. Org. Chem. 43 (1978) 1064-1071.

[9] C. G. Screttas, M. Micha-Screttas, Markownikoff two-step hydrolithiation of .alpha.-olefins. Transformation of secondary and tertiary alkyl phenyl sulfides to the relevant alkyllithium reagents, J. Org. Chem. 44 (1979) 713-719.

[10] T. Fujiwara, Y. Kato,T. Takada, Ring-Closing Metathesis of Titanium-Carbene Complexes Prepared from Thioacetals Having a Carbon-Carbon Double Bond, Tetrahedron. 56 (2000) 4859- 4869.

[11] D. Seebach, R. Bürstinghaus, S-Methyl thiocarboxylates from aldehydes and ketones through ketene thioacetals. Reductive nucleophile thiocarbonylation, Synthesis. 31 (1975) 461-462.

[12] D.J. Ager, A new method for preparing 1-phenylthio-1-trimethylsilylalkanes: the preparation of $\hat{I} \pm$ - silylcarbanions and olefins, Tetrahedron Lett. 22 (1981) 2932 -2926.

[13] M.M. Khodaei, P. Salehi, M.A. Zolfigol, S. Sirouszadeh, Efficient synthesis of 3,4dihydropyrimidin-2 $(1 \mathrm{H})$-ones by aluminium hydrogensulfate in solution and under solvent free conditions, Polish J. Chem. 78 (2004) 385-388.

[14] E.J. Corey, D.J. Seebach, Phenylthiomethyllithium and Bis(phenylthio)methyllithium Org. Chem. 31(1966) 4097-4099.

[15] H.I. Mosberg, J.R. Omnaas, A. Goldstein, Structural requirements for $\delta$ opiod receptor binding, Mol. Pharmacol. 31 (1987) 599-602.

[16] A. Fürstner, A. Hupperts, A. Ptock, E. Janssen, "Site Selective" Formation of Low-Valent Titanium Reagents: An "Instant" Procedure for the Reductive Coupling of Oxo Amides to Indoles J. Org. Chem. 59 (1994) 5215-5229.

[17] G. Delogu, O.D. Lucchi, P. Maglioli, Asymmetric reactions of thioacetals and their S-oxides derived from 1,1'-binaphthalene-2,2'-dithiol, J. Org. Chem. 60 (1991) 4467-4473.

[18] M. Ueki, T. Ikeo, K. Hokari, K. Nakamura, A. Saeki, H. Komatsu, A new efficient method for $\mathrm{S}-\mathrm{CH}_{2}-\mathrm{S}$ bond formation and its application to a Djenkolic acid containing cyclic Enkephalin analogue, Bull. Chem. Soc. Jpn. 72 (1999) 829-838.

[19] R.S. Asquith, Chemistry of Natural Protein Fibers, Springer Science \& Business Media, Berlin, 2012. 
[20] N. Greenspoon, R. Hershkoviz, R. Alon, E. Gershonov, B. Lavie, O. Lider, Novel psi-S-CH peptide-bond replacement and its utilization in the synthesis of nonpeptidic surrogates of the Leu-Asp-Val sequence that exhibit specific inhibitory activities on CD4+ T cell binding to fibronectin, Int. J. Pept. Protein Res. 43 (1994) 417-424.

[21] A.C.T. North, D.C. Phillips, F.S. Mathews, A semi-empirical method of absorption correction, Acta Crystallogr, Sect. A. 24 (1968) 351-359.

[22] Bruker, SADABS (Version 2007/4). Bruker AXS Inc., Madison, Wisconsin, USA, 2008.

[23] A. Altomare, M.C. Burla, M. Camalli, G.L. Cascarano, C. Giacovazzo, A. Guagliardi, A.G.G. Moliterni, G. Polidori, R. Spagna, A new tool for crystal structure determination and refinement, J. Appl. Crystallogr. 32 (1999) 115-119.

[24] G.M. Sheldrick, SHELXL 97, Program for Crystal Structure Refinement, Univ. of Gottingen, Germany, 1997.

[25] L.J. Faruggia, ORTEP-3 for Windows, University of Glasgow, Scotland, UK, 1999.

[26] N. Alexander, K. Ramalingam, C. Rizzoli, Supramolecularly Linked Linear Polymers of Thallium(I) Dithiocarbamates: Steric Influence on the Supramolecular Interaction of Methyl and Ethylcyclohexyl Dithiocarbamates of Thallium(I), Inorg. Chim. Acta. 365 (2011) 480483.

[27] S. Sivasekar, K. Ramalingam, C. Rizzoli, Metal dithiocarbamate precursors for the preparation of a binary sulfide and a pyrochlore: Synthesis, structure, continuous shape measure and bond valence sum analysis of antimony(III) dithiocarbamates, Polyhedron, 85(8) (2015) 598-606.

[28] G. S. Sivagurunathan, K. Ramalingam, C. Rizzoli, Continuous Shape Measure of electronic effect free steric distortions in tris(dithiocarbamato)indium(III): Synthesis, spectral, electrochemical, single crystal X-ray structural investigations and BVS calculations on tris(dithiocarbamato)indium(III) complexes, Polyhedron, 72 ( 2014) 96-102.

[29] G. S. Sivagurunathan, K. Ramalingam, C. Rizzoli, Nanothallium(III) sulfide from dithiocarbamate precursors: Synthesis, single crystal X-ray structures and characterization, Polyhedron, 65 (2013) 316 - 321.

[30] S. Sivasekar, K. Ramalingam, C. Rizzoli, N. Alexander, Synthesis, structural, Continuous Shape Measure and bond valence sum characterization of bismuth(III) complexes of substituted dithiocarbamates and their solvothermal decomposition, Inorg. Chim Acta, 419 (2014) 82-88. 